\title{
Memorias protésicas: Posmemoria y cine documental en la España contemporánea ${ }^{1}$
}

\author{
Laia QuíLEZ EsTeVE \\ Universitat Rovira i Virgili (Tarragona) \\ laia.quilez@urv.cat
}

\section{Resumen}

Este artículo trata de aproximarse a la representación de la guerra civil española y el franquismo en el cine realizado por la generación de los nietos de las víctimas y supervivientes de ese turbulento capítulo de la historia. Mediante el análisis de tres documentales (Haciendo memoria, Nadar y Tierra encima) se intentará cartografiar los modos con los que estos jóvenes cineastas trabajan la memoria de esos años de represión y las cuestiones alrededor del terreno de la memoria, la historia y el lenguaje cinematográfico que plantean en sus metrajes.

Palabras clave: Posmemoria, guerra civil, franquismo, cine documental

\section{Prosthetic Memory: Postmemory and Documentary Film in Contemporary Spain}

\begin{abstract}
This paper approaches the representation of the Spanish Civil War and Franco's dictatorship in the films directed by the generation of grandchildren of the victims and survivors of that turbulent chapter of history. By analyzing three documentaries (Haciendo memoria, Nadar y Tierra encima) we will try to map the ways in which these young filmmakers work the memory of those years of repression. We also address the way they reflect on memory, history and visual language.
\end{abstract}

Key Words: Postmemory, Civil War, Franco's Dictatorship, Documentary Film

\section{Referencia normalizada:}

Quílez Esteve, L. (2013) Memorias protésicas: Posmemoria y cine documental en la España Contemporánea. Historia y Comunicación Social. Vol. 18 Nº Especial Octubre. Págs. 387-398

Sumario: 1. Introducción. 2. Metodología: Hacia una teoría de la posmemoria. 3. Análisis fílmico: Memorias protésicas. 3.1. Usos y desusos del material de archivo: Haciendo memoria, de Sandra Ruesga 3.2. Posmemoria y juegos de la imaginación: Tierra encima, de Sergio Morcillo 3.3. Duelo e identidad en los documentales de búsqueda: Nadar, de Carla Subirana. 4. Conclusiones. 5. Bibliografía.

\section{Introducción}

No es novedoso constatar que actualmente el cine documental está gozando de una inédita popularidad, seguramente porque se ha convertido en un vehículo creativo e innovador a la hora de plasmar la realidad social y de evocar el pasado. El 
abaratamiento de los costes de producción y la maleabilidad que permite el sistema de registro y posproducción digital, han diversificado las voces que se vehiculan en este tipo de cintas, ahora mucho más ricas en cuanto a los puntos de vista, recursos estilísticos y estrategias narrativas se refiere. La incorporación de procedimientos típicamente posmodernos, como son el pastiche, la intertextualidad, la hibridación genérica, la autoficción o la discontinuidad visual y narrativa, ha vuelto mucho más opaca e indirecta la relación que el documental -un tipo de cine que etimológicamente sigue remitiendo a su función probatoria- mantiene con el mundo histórico.

Si nos fijamos en el panorama cinematográfico español, concretamente en la representación documental de la guerra civil y el franquismo, descubrimos cómo en los últimos años están emergiendo varios trabajos que se aproximan a aquellos años desde una mirada mucho más crítica, subjetiva y experimental que la que en general ha caracterizado a las producciones anteriores. Se trata de cintas firmadas por la generación de los nietos de aquellos que sufrieron, muchas veces en carne propia, el terror y la violencia de la gerra y la posguerra. Títulos como Muerte en El Valle (C. Hardt, 1996), Tierra encima (S. Morcillo, 2005), Haciendo memoria (S. Ruesga, 2005), Nadar (C. Subirana, 2008), Bucarest. La memoria perdida (A. Solé, 2008), El muro de los olvidados (J. Gordillo, 2008) o Cosas raras que pasaban entonces (F. Verdés y P. Baur, 2008) tienen en común el hecho de recuperar el pasado desde una distancia generacional (desde una 'posmemoria') respecto a los hechos históricos evocados que dota a estos trabajos de una mirada bastante diferente (políticamente más crítica y a la vez también más intimista y autobiográfica) que la que puede dar el superviviente o el testigo ocular de los hechos.

La presente investigación pretende aproximarse a este tipo de trabajos audiovisuales que, por la experiencia de vida y las marcas socioculturales propias de la generación a la que pertenecen sus autores, consideramos que constituyen por sí solos un bloque aparte dentro de la historia del cine documental sobre la guerra civil y el franquismo. La falta de una bibliografía que indague con profundidad en este corpus de un modo profuso - es decir, que vaya más allá de la reseña periodística- nos ratifican la necesidad reflexionar sobre las múltiples cuestiones que tales documentales plantean alrededor del terreno de la memoria, la historia y el lenguaje audiovisual. El objetivo último de nuestro artículo es, por tanto, acercarnos a los documentales más representativos realizados en España por esta tercera generación durante los últimos quince años para cartografiar los modos con los que estos cineastas trabajan la memoria de esos años de represión. Trazando una especie de geografía de la 'posmemoria' en el cine documental español, intentaremos determinar en qué grado estas películas cuestionan y reelaboran elementos, herramientas y términos tan comunes en la representación de la memoria y la historia como son los de la validez del testimonio oral, los usos y abusos de la imagen de archivo, la mitificación de las víctimas o la inclusión de la ficción para apelar a la memoria personal y colectiva. 


\section{Metodología: Hacia una teoría de la posmemoria}

Abordar los documentales sobre la guerra civil y el franquismo realizados en los últimos años por nietos de supervivientes y víctimas mortales de la guerra y la posguerra españolas, implica poner sobre la mesa el tema de la posmemoria, un concepto que no por casualidad viene tratado la mayor parte de las veces en los estudios realizados sobre el Holocausto. En efecto, a raíz del cambio de paradigma que, a partir de los años ochenta, opera en los discursos de la Shoah -y en el que la posibilidad o imposibilidad de representar esa barbarie viene sustituida por la pregunta de cómo hacerlo-, se empieza a reflexionar sobre las producciones realizadas ya no por quienes sobrevivieron a los campos de concentración, sino por quienes heredan el relato de esa experiencia traumática.

En el plano teórico, y como consecuencia de la proliferación de obras de todos los géneros y formatos firmadas por la generación siguiente a la que logró salvarse de las cámaras de gas, empiezan a publicarse un conjunto de ensayos, artículos y libros monográficos que versan sobre el proceso a través del cual la memoria directa de aquella experiencia se transmite a los que nacieron después, así como también sobre los modos en qué éstos plasman esa 'memoria heredada' en sus creaciones y productos culturales. Son todas ellas reflexiones que traen a colación cuestiones similares a las suscitadas en los estudios concernientes al terreno de la memoria, y por tanto relativas a los límites de la representación de lo traumático, a los usos y abusos de los materiales de archivo, a las fisuras de la voz testimonial, al problemático papel de la imagen o a la crisis del sujeto a la hora de configurar un relato verosímil de los hechos. Sin embargo, dichas reflexiones se centran también en los problemas concretos con los que se encuentra esta segunda y tercera generación a la hora de vehicular artísticamente este tipo de memoria, referida también, por los principales teóricos en este campo, como "memoria agujereada" (Raczymow, 1994), "memoria heredada" (Lury, 1998), "memoria tardía" y "memoria protésica" (Landsberg, 2004), "memoria vicaria" (Young, 2000), o, finalmente, "posmemoria" (Hirsch, 1997), la etiqueta que utilizaremos de ahora en adelante.

El auge que en los últimos años ha tenido este tipo de estudios y producciones culturales en la sociedad contemporánea puede explicarse, especialmente en el caso de España, por la paulatina e inevitable desaparición de los supervivientes directos del horror. En efecto, la muerte de quienes lo sufrieron o lo perpetraron conlleva, irrefutablemente, "la pérdida de la memoria colectiva de la cual éstos son detentores" (Chéroux, 2007: 221) y la traslación, en consecuencia, de la prueba al documento, del testimonio a la representación. Es precisamente a raíz de este progresivo silenciamiento de las víctimas que tiene lugar una lenta pero imparable sustitución de la "memoria comunicativa" (o colectiva) por la "memoria cultural" (o histórica), es decir, de la memoria transmitida por los testigos directos del hecho histórico en cuestión, por una memoria basada en las producciones culturales que, partiendo de los relatos conservados de esos testigos, garantizan la continuidad de la transmisión de esa memoria en el futuro. Desde esta perspectiva, el puente por excelencia - , 
en este caso, el receptáculo- que hereda esta memoria comunicativa y la transforma en memoria cultural, lo constituye, precisamente, la figura del allegado, esto es, un "prójimo privilegiado" en tanto que se ubica "en una gama de variación de las distancias en la relación entre el sí y los otros" (Ricoeur, 2003: 172). Es así como el hijo, el nieto o el sobrino del superviviente se ven impelidos a escuchar a ese otro prójimo que los supera en edad y en experiencia para, de este modo, convertirse en garantes de la memoria familiar que, a partir de la reelaboración crítica, ética y artística a la que la sometan, se inscribirá en esa memoria cultural a la que hemos hecho alusión líneas más arriba.

No por su carácter mediado e indirecto, la posmemoria tiene menos fuerza o compromiso que los trabajos de memoria propiamente dichos. De hecho, la posición crítica e interrogante hacia una representación sin fisuras del pasado que plantean estos trabajos los revaloriza y los desmarca de las memorias vivenciales. Para alcanzarla, estas segundas y terceras generaciones hacen uso de todas aquellas herramientas, medios y expresiones que han marcado y marcan su descubrimiento y aprendizaje de esos pasados ajenos. Fotografías, películas, pinturas, obras de teatro, animaciones audiovisuales, etc., conforman para ellos una constelación de representaciones en las que la imagen les permite acceder más fácilmente a la memoria de sus antepasados, al tiempo que les promete una transmisión de la misma mucho más crítica que la que podría aportarles el documento escrito o el archivo entendido en sentido estricto.

\section{Análisis fílmico: Memorias protésicas}

\subsection{Usos y desusos del material de archivo: Haciendo memoria, de Sandra Ruesga}

El hecho de que los cineastas que firman estos documentales de tercera generación no dispongan de una memoria directa del trauma (de la desaparición, de la tortura, del asesinato, del exilio) que luchan por representar en sus trabajos, los empuja a recuperar numerosos y heterogéneos materiales de archivo que acrediten probatoriamente ese pasado lejano e incluso extraño para algunos de ellos. Sin embargo, la apropiación que estos autores suelen hacer de este tipo de material es, sin lugar a dudas, altamente productiva. Así es, la resignificación a la que someten las imágenes heredadas -ya sea de los medios de comunicación, ya sea de los álbumes familiares o de los videos caseros- para que éstas no acaben siendo víctimas de un consumo automatizado y acrítico, corre en paralelo y se explica por el hecho que todos ellos han nacido y crecido en una cultura que justamente privilegia la expresión audiovisual. Consumidores naturales y asiduos de televisión, cómics y cine, no es extraño que la mayor parte de estos jóvenes recurra a las imágenes como instrumentos para vehicular no sólo su voluntad de conocer el pasado y vincularse a él en tanto que raíz y origen, sino también para proyectar sus afectos, miedos, necesidades y deseos de su presente. 
Uno de los casos que mejor ilustra los nuevos usos que la generación de los nietos otorga en España a las imágenes familiares y de archivo es Haciendo memoria, un cortometraje incluido en el proyecto audiovisual Entre el dictador y yo, en el que a partir de la premisa 'Cuál fue la primera vez que oí hablar de Franco', seis jóvenes directores realizan sendas piezas documentales sobre su relación -siempre en segundo grado- con el pasado de la dictadura.

Después de unos títulos de crédito hechos a partir de letras recortas, como si con ello Ruesga quisiera avisar al espectador de la domesticidad que impregna el film, aparece, en un primer plano y mirando directamente a cámara, una pequeñísima Ruesga, de apenas cuatro años, que parece decir 'hola' a cámara. Sin embargo, no es la voz de la niña la que registra la banda sonora de la película, sino la de la cineasta en el presente del montaje, saludando -y con ello doblando con un 'hola' adulto a la niña que ocupa la pantalla- a su padre, con quien mantiene a partir de ese momento una conversación telefónica.

Todo el cortometraje de Ruesga sigue la misma estructura: en pantalla van sucediéndose imágenes extraídas de los videos caseros de la familia de la cineasta, mientras que en la banda sonora se desarrolla un incómodo diálogo entre ella y sus progenitores que contrapuntea, por tenso contraste, la inocencia y felicidad inscriptas en esas escenas de su infancia y adolescencia. Así, las excursiones que la familia hacía al Valle de los Caídos, en las que vemos a una graciosa Ruesga caminando con su hermano por los alrededores de esa tumba monumental, son reprendidas por una joven y obcecada cineasta que requiere a sus padres el motivo último de esas salidas. "Es porque lo teníamos al lado e íbamos de excursión", intenta justificarse su padre.

Focalizando su mirada en aquello más íntimo y familiar, la cineasta madrileña lucha con tenacidad contra la amnesia de un importante segmento de la generación anterior a la suya: aquél que, sin aplaudir abiertamente el franquismo, lo toleró sin cuestionar sus métodos. Ruesga parece escandalizarse con el hecho de que su madre sólo se percatará de la falta de libertades que constreñía al país con lo que a la censura cinematográfica se refiere; o que considerara un simple rumor $-y$ por tanto, indigno de su atención- las torturas que sufrían los presos políticos; o que su padre no le diera importancia alguna al monumento a Onésimo Redondo que preside el Cerro de San Cristóbal y que funciona de telón de fondo de alguno de los videos de la familia. "Yo no he tenido ningún interés en sacar adelante la historia. Si vosotros tampoco lo habéis tenido, pues el desinterés ha sido mutuo", sentencia incómodo el padre de Ruesga en un momento de la cinta. Sin embargo, la voluntad de la hija por saber y por cuestionar la pasividad de sus progenitores frente a un pasado marcado por el totalitarismo es evidente. Y lo es no sólo mediante la tensa conversación que mantiene con ellos (y que tiñe de lobreguez unos fotogramas que en su origen sólo denotan felicidad y pureza), sino también, y en última instancia, a través del trabajo de recontextualización que lleva a cabo con unas imágenes que ahora se nos presentan convertidas en un documento de alto valor colectivo. Pues aunque el film parezca ser únicamente una muestra del desencuentro entre generaciones, termina convirtiéndose en mucho más, pues también es "una minicrónica de la vida de España durante 
el tardofranquismo" (Cuevas, 2012: 119) que nos empuja a preguntar quién somos y de dónde venimos ${ }^{2}$.

\subsection{Posmemoria y juegos de la imaginación: Tierra encima, de Sergio Morcillo}

Uno de los rasgos más destacados de los documentales que en España se están produciendo alrededor de la posmemoria es la interrelación que en muchos de ellos tiene lugar entre lo tradicionalmente considerado como documental y aquellos elementos característicos del mundo de la ficción -como podrían ser la actuación, la puesta en escena, las recreaciones e, incluso, la invención de historias y personajes que nunca existieron.

En la producción documental española sobre la representación del trauma de la guerra civil, destaca una película que, utilizando las convenciones del cine documental, se insiere de lleno en el ámbito de la ficción, concretamente en el del mockumentary, también conocido como fake o falso documental, esa especie de híbrido genérico en el que la revelación del carácter ficticio del material filmado muchas veces no tiene lugar hasta la aparición de los créditos finales. Nos estamos refiriendo a Tierra encima, un mediometraje protagonizado por alguien que bien podría haber existido: Félix Costa Pujadas.

Costa es un anarquista catalán que, ya octogenario, rememora desde la Barcelona contemporánea la historia de su militancia en las Juventudes Libertarias, su papel en la guerra civil española, su encarcelamiento en un campo de concentración francés, su exilio canadiense y el reciente y asombroso descubrimiento que ha hecho con respecto a su biografía. Gracias a un viaje que su nieto realiza a la ciudad condal y casi por casualidad, Félix se percata de que su condición en la administración pública es la de una víctima mortal de la guerra, concretamente de uno de los muchos fusilamientos que tuvieron lugar en el Camp de la Bota en 1939. Así lo ratifica la inscripción de su nombre en el monumento conmemorativo que se erige en el Fossar de la Pedrera en memoria de los republicanos caídos durante la contienda española y los años de represión franquista.

A lo largo de los cuarenta minutos que dura el documental, el espectador acompañará a Félix Costa en su recorrido por los lugares de la ciudad que puntearon su periplo vital de aquellos años convulsos. El primero que visita es lo que fuera el arenal del Camp de la Bota, una zona que en los años cuarenta quedaba lo suficientemente apartada del núcleo urbano para que pocos se percataran de los fusilamientos que allí se perpetraban. El horror, la sangre y la muerte que impregnaron ese paraje durante aquellos años se han desvanecido por completo. En su lugar hoy se asienta una tranquila y cimentada plaza, presidida por el Monumento de la Fraternidad. Erigido en 1992 a instancia del Ayuntamiento de Barcelona, este monumento simboliza aquello contra lo que Costa -y en última instancia, Morcillo- quieren combatir: la memoria institucionalizada, cuya lectura del pasado tiende siempre a la simplificación y reduce lo acontecido a un estanco, artificioso, mediatizado e inmutable continente de verdades eternas e incuestionables. Contra ello, Tierra encima parece imponerse 
como un 'contramonumento', esto es, como un espacio de diálogo y análisis crítico que pueda excavar y horadar esa 'tierra' -ese olvido- que peligra en caer encima de la memoria de aquellos años. Y Morcillo lo consigue no sólo escuchando el detenido relato de su ficticio testimonio, sino también recurriendo a la recreación de aquellos momentos del pasado de los cuales, por la propia naturaleza de los mismos, no se ha conservado ninguna prueba audiovisual tangible. Así, utilizando como marco el visor de la segunda cámara del equipo, y después de que Costa observe lo que allí se visualiza - el monumento de la Plaza del Fórum-, se recrea, como si de un sortilegio de la imaginación y la memoria se tratara, uno de los muchos fusilamientos que pudo haber tenido lugar en ese punto de la geografía barcelonesa. Teñidos por una artificiosa -por marcada- luz azulada, un pelotón de soldados se dispone a disparar a tres detenidos. Tras la orden de 'fuego', se oye un estruendo y, acto seguido, el mar. De los cadáveres sólo se nos muestra, después, una mano abierta, sin vida, que en su descontextualización, en su aislamiento, representa metonímicamente a todos los cuerpos caídos, a todos los hombres fusilados y, en última instancia, a todas sus familias.

Tierra encima termina con la llegada de Costa al Fossar de la Pedrera, situado detrás del Cementerio de Montjuic. Lenta y dificultosamente, el octogenario sube el empedrado camino que lo conducirá a las austeras columnas dedicadas a las víctimas de la contienda. Mientras en over se escucha una voz de mando recreada para tal ocasión, Costa lee las inscripciones que se despliegan en el referido monumento. A través de ellas descubriremos, en el plano final, que la identidad de Félix Costa Pujadas ha sido construida artificialmente, a partir del nombre y apellidos de tres republicanos distintos. Es así cómo se desvela el carácter ficticio de la historia central de la película, su condición de escritura híbrida: Félix Costa no existió, su relato de vida ha sido inventado, si bien es riguroso y cierto el resto de informaciones sobre aquel periodo histórico que nos viene dado tanto por las imágenes de archivo que van apareciendo a lo largo de la cinta, como por la narradora extradiegética y otros testimonios que sí son quiénes dicen ser (como el historiador Josep Marià Solé o los tres ex militantes libertarios con los que Costa charla en un momento del film).

Tierra encima puede interpretarse, pues, como una especie de experimento en el que Morcillo parece querer demostrar los olvidos y las medias verdades (o medias mentiras) inherentes a las representaciones más mediáticas de la historia. De hecho, en un escrito del cineasta publicado en el Butlletí Estel Negre, subraya la necesidad de "crear un espectador receptor crítico, que cuestione los mensajes, tanto su contenido como su forma" (2006: 3). El espectador de Tierra encima sin duda lo es, pues el alto grado de autorreflexividad y subversión que subyace en el metraje nos desafía a combatir las limitaciones de la memoria oficial y a sacudirnos esa 'tierra' que muchas veces puede terminar cubriendo un pasado que es necesario, siempre, recordar.

\subsection{Duelo e identidad en los documentales de búsqueda: Nadar, de Carla Subirana}

Dentro del ambiguo y vasto campo del documental subjetivo y constriñéndonos todavía al corpus de documentales de la guerra civil y el franquismo trabados bajo el paraguas de la posmemoria, destaca Nadar, un largometraje que pivota alrededor de 
la transmisión transgeneracional de la memoria, del retrato familiar y de la búsqueda identitaria. Como ocurre en otros documentales de 'búsqueda familiar's, aquí la inclusión de testimonios ya no se justifica por los datos que puedan dar sobre la trayectoria militante y/o política del desaparecido, sino que su presencia cobra sentido precisamente porque inciden (o son requeridos por estos cineastas a que lo hagan -a veces con poco éxito) en el lado más humano y en la vida cotidiana, sentimental y familiar de esos 'íntimos extraños' en que se han convertido sus respectivos abuelos.

Crecida sin la figura de su abuelo y sin la de su padre, el 'yo' que protagoniza Nadar va moldeándose y encontrando su lugar en el mundo discursivo a partir de la biografía de ese 'otro' que le legó mucho más que un apellido. Es con él, sobre todo, con quien Subirana departe, en una especie de diálogo fantasmal en el que el protagonismo de quienes sobrevivieron a los duros años de la guerra y la posguerra y ahora dan testimonio la película está en función, fundamentalmente, de la cantidad y calidad de la información que puedan aportar con respecto a esa figura que tanta curiosidad despierta a la joven realizadora. Es así como ese 'tú' con el que trata de comunicarse Subirana se presenta en el film como un sujeto misterioso y por ello fascinante, cuya estela sigue décadas después y con notorio encandilamiento una nieta dispuesta, no sólo a hacerle caer la máscara, sino también a devolverle la voz (ya sea rastreando diarios y archivos públicos en los que puedan hallar cualquier dato relativo a su historia, ya sea recuperando el recuerdo que de ellos conservan quienes les conocieron). Y es precisamente a esta amalgama de fragmentos del pasado a la que Subirana interpelará con la terquedad de quien lleva toda su vida creciendo entre interrogantes de difícil o imposible respuesta.

No es baladí que Nadar empiece con una escena de Subirana zambulléndose en una piscina. Como esa agua que la acoge, y bajo la cual sólo escucha el sonido de sus propios latidos, la memoria que tratará de aprehender la directora se tornará líquida ya desde el principio de su investigación. Subirana quiere y necesita saber qué pasó realmente con su abuelo, Juan Arroniz, condenado a muerte por atracar una zapatería en mayo de 1940 y fusilado poco después por el recién estrenado régimen franquista. Pero su abuela Leonor, la mujer que más completas e inmediatas respuestas podría darle sobre ese misterioso personaje, se ha quedado justamente sin aquello que la cineasta con más afán persigue: los recuerdos. Leonor padece Alzheimer y, como la madre de Subirana -afectada de demencia presenil-, irá olvidando poco a poco su pasado y su presente. Ante estas limitaciones, la cineasta decide continuar la investigación fuera de los muros de su hogar. Así, sospesará largamente con Joaquim Jordà la hipótesis de que su abuelo en realidad formara parte de la resistencia y que el atraco que cometió se pudiera deber a motivos políticos; o visitará el pueblo de Mont-ros, en el que descubrirá que sus abuelos nunca llegaron a casarse porque Juan ya había contraído matrimonio anteriormente con otra mujer; o hablará con su tía Hermínia, que le confesará que su abuelo le fue siempre infiel a Leonor; o finalmente mantendrá una infructífera y algo encrespada entrevista con el escritor y militante anarcosindicalista Abel Paz, que la despachará reconociéndole no entender lo que le está preguntando y no saber "nada de nada". 
Ante esta amalgama de voces, testimonios y opiniones, Subirana va forjando en su imaginación la imagen de su abuelo, que luego podrá comparar con la única fotografía que logra conseguir de él, tras localizar a su tía abuela, Dolores Arroniz, e irla a ver a su casa. También podrá hacerlo el espectador, pues ese intrépido galán bogardiano que Subirana fabula que fue su abuelo viene representado en pantalla en diversas ocasiones, cuando protagoniza media docena de escenas en blanco y negro en las que se recrean, por medio de actores y una puesta en escena que recuerda la estética de las películas clásicas de cine negro, las distintas y posibles situaciones que pudo vivir su abuelo: el atraco a mano armada, los encuentros amorosos con Leonor, el viaje en tren a Mont-ros de la pareja -cuando ella estaba embarazada de seis meses-, o su encierro carcelario justo antes de morir. Sin embargo, la búsqueda de ese rostro, de esa historia, de esa biografía, no puede más que terminar en fracaso: "él sigue siendo un extraño para mí", concluye Subirana en el desenlace del film, antes de anunciar el fallecimiento de su abuela y antes también de sumergirse de nuevo en las aguas de una piscina en penumbra. La distancia generacional que horada su memoria parece representarse en ese salto a las profundidades acuáticas que lleva a una generación (la suya) a explorar en el pasado de otra (la de su madre y abuela). Así lo confirma la penúltima escena del documental, cuando la cineasta decide filmar a su hijo Mateo -nacido durante la realización de la película-, haciendo sus primeros escarceos en el agua. Será el pequeño y su generación quién deberá seguir alimentando en el futuro el trabajo por una memoria por la que hoy la de Subirana lucha para que perviva.

\section{Conclusiones}

Referirnos a la 'posmemoria' sobre la guerra civil española y el franquismo labrada por lo que hemos convenido en llamar 'tercera' generación, es tener presente un grupo de producciones cinematográficas que, en última instancia, persiguen un doble objetivo: por un lado, rendir homenaje -aunque en algunos casos sea cuestionándolas- a las víctimas y supervivientes de la guerra y la dictadura; $y$, por otro lado, iniciar una búsqueda identitaria de unos orígenes sesgados por el terror totalitario, especialmente en el caso de aquellos documentales que, como Nadar, registran un tipo de problemáticas estrechamente vinculadas con las relaciones de filiación y con la memoria familiar.

Tal y como sucede en otras narrativas, como las producidas por hijos de víctimas mortales y supervivientes del Holocausto, también en nuestro contexto particular la imagen se convierte en uno de los soportes por excelencia para vehicular las ausencias, los interrogantes y los descubrimientos que sobre la guerra y la dictadura han hecho y siguen haciendo estos jóvenes realizadores. Fotografías familiares, películas caseras, recreaciones, entrevistas filmadas y escenas con una cuidada puesta en escena se aglutinan en casi todas las películas referidas en nuestro corpus. Conjugando, pues, lo legado (el álbum familiar, las cartas personales, las historias o versiones y relatos que conservan y les regalan las generaciones anteriores), con lo genuinamente propio 
(los recuerdos personales, pero también las ficciones y fabulaciones elaboradas como explicación a un pasado borroso o totalmente desconocido), estos cineastas convierten el lenguaje audiovisual en el medio por excelencia para describir y pensar el pasado.

De la pesquisa en sentido estricto a la experimentación elevada al máximo nivel, del documental como arma fundamentalmente política al cine entendido como herramienta de introspección y autoconocimiento, de la estética de las home movies a la omnipresencia testimonial, del homenaje al desaparecido a la interpelación directa a las generaciones precedentes, los artefactos culturales con los que en los últimos años los 'nietos' han tratado de evocar un pretérito para ellos irresolublemente imperfecto, por fortuna no ha parado de crecer. Y decimos por fortuna porque este tipo de producciones documentales ha logrado encauzar lo político en unas formas de representación que, además de originales, recurren a temáticas marcadamente personales -como serían la constitución de la subjetividad o las relaciones familiares-sin desvincularse de la reflexión sobre un capítulo de la historia que sigue condicionando nuestro presente. La performación, la ironía, el fracaso, el viaje interior y la experimentalidad que nutre la filmografía de todos ellos no es incompatible, más bien al contrario, con la honestidad que debe conllevar toda aproximación crítica al pasado -y más cuando éste viene acompañado por la violencia y el trauma. Con ella esta joven generación ha logrado afianzar una voz que, pese a no sustentarse tanto en la rotundidad del eslogan político como en la afectividad del discurso familiar, propone una 'verdad' igualmente válida de la realidad española de los años de la guerra civil y el franquismo.

\section{Referencias bibliográficas}

AMADO, A. (2005). "Las nuevas generaciones y el documental como herramienta de historia". En ANDÚJAR, A.; D’ANTONIO, D.; DOMÍNGUEZ, N. (et.al.) (2005). Historia, género y politica en los 70', Buenos Aires: Feminaria Editora. p. 221-240.

CHÉROUX, C. (2007). “¿Por qué sería falso afirmar que después de Auschwitz no es posible escribir poemas?”. En LORENZANO, S.; BUCHENHORST, R. (eds.) (2007). Políticas de la memoria. Tensiones en la palabra y la imagen. Buenos Aires: Gorla; México: Universidad del Claustro de Sor Juana. p. 210-230.

CUEVAS, E. (2012). "El cine autobiográfico en España. Una panorámica". En RILCE, Revista de Filología Hispánica, no 28.1, Pamplona: UNAV. p. 106-125.

GÓMEZ VAQUERO, L. (2009). "Hacer visible el trauma: invocación de la memoria en la producción desde los años setenta en España". En Secuencias: revista de historia del cine, $\mathrm{n}^{\circ}$ 30, Madrid: UAM. p. 94-117.

HIRSCH, M. (1997). Family Frames: Photography, Narrative, and Postmemory. Cambridge (Mass.) y Londres: Harvard University Press. 
LANDSBERG, A. (2004). Prosthetic Memory: The Transformation of American Remembrance in the Age of Mass Culture. Nueva York: Columbia University Press.

LURY, C. (1998). Prosthetic Culture: Photography, Memory, Identity. Londres: Routledge.

MORCILLO, S. (2006). "La sempre present manipulació de la memòria histórica”. En Butlleti Estel Negre, $\mathrm{n}^{\circ} 164$. Disponible en: http://www.estelnegre.org/ butlleti/164.pdf. [25/08/2013].

RACZYMOW, H. (1994). "Memory Shot through with Holes". En Yale French Studies, ${ }^{\circ}$ 85, New Haven: Yale University. p. 98-106.

RICOEUR, P. (2003). Historia, memoria, olvido. Madrid: Trotta.

YOUNG, J. (2000). At Memory's Edge: After-Images of the Holocaust in Contemporary Art and Architecture. New Haven \& London: Yale University Press.

\section{Notas}

1 La realización de este artículo se enmarca en el desarrollo del proyecto de investigación financiado por el Banco Santander y la Universitat Rovira i Virgili, "Memorias en segundo grado: Posmemoria de la guerra civil y el franquismo en la España del siglo XXI" (2013LINE-01).

2 Si Haciendo memoria vehicula su narrativa a través de la reapropiación de metraje heredado, Cosas raras que pasaban entonces (F. Verdés y P. Baur, 2012) prescinde de cualquier referencia a la imagen fílmica y audiovisual del pasado e igualmente construye un sólido discurso alrededor de la memoria y el archivo. De un modo similar al que hallamos en Shoah (C. Lanzmann, 1983), Verdés y Baur transportan a Ramón Sangés, el protagonista nonagenario del documental, a los espacios donde padeció los horrores de la guerra y la posguerra. En su caso, sin embargo, no les interesa tanto el discurrir verbal de Sangés como la puesta en situación del mismo setenta años después de los acontecimientos. En este sentido, Cosas raras que pasaban entonces no trata tanto de hacer revivir el horror de la guerra, sino más bien de reflexionar sobre el paso del tiempo y las dificultades de la memoria por evocar el pasado.

3 En este espacio es necesario citar también los documentales Muerte en El Valle (C. M. Hardt, 1996), en el que la cineasta viaja a un pueblo de León para esclarecer la verdad sobre la muerte de su abuelo, asesinado en 1948 por la Guardia Civil; Bucarest, la memoria perdida (A. Solé, 2008), un recorrido personal de su director por la historia de su familia y de su padre, el político Jordi Solé Tura, afectado por la enfermedad del Alzheimer; El muro de los olvidados (J. Gordillo, 2008), un documental en el que el realizador francés emprende una búsqueda relacionada con sus orígenes genealógicos (el lugar donde está enterrado su abuelo) y también con la memoria histórica y la reparación de las barbaries cometidas durante y después del franquismo; y, finalmente, Pepe el andaluz (A. Alvarado y C. Barquero, 2012), la lucha documentada de Alejandro Alvarado por descubrir quién fue en realidad su abuelo, José Jódar, un malagueño que emigró a Argentina después de la guerra civil y nunca más regresó a España. 


\section{La autora}

Laia Quílez Esteve es licenciada en Comunicación Audiovisual por la Universitat Autònoma de Barcelona y en Teoría de la Literatura y Literatura Comparada por la Universitat de Barcelona. Es Doctora en Comunicación por la Universitat Rovira i Virgili, donde ejerce de profesora. Autora de una tesis doctoral sobre la posmemoria en el cine documental argentino, actualmente pertenece al grupo de investigación ASTERISC y dirige el proyecto "Memorias en segundo grado: Posmemoria de la guerra civil y el franquismo en la España del siglo XXI". Ha publicado en revistas nacionales e internacionales (Archivos de la Filmoteca, Quaderns de Cine, Studies in Hispanic Cinemas) y ha participado en varios libros colectivos (Cineastas frente al espejo, La risa oblicua, El cine argentino de hoy, Historias de la pequeña pantalla). 